\title{
Mass Transfer Management and Deposition of Contaminants within Car Road Zones
}

\author{
Volodymyr Ivanyshyn \\ Rector of \\ State Agrarian and Engineering \\ University in Podillia \\ Kamianets-Podilskyi, Ukraine \\ main@pdatu.edu.ua \\ Anatolii Rud \\ Department of Agricultural Machinery \\ and Mechanization Technology \\ State Agrarian and Engineering \\ University in Podillia \\ Kamianets-Podilskyi, Ukraine \\ anatoliyrudj@gmail.com
}

\author{
Lesia Sheludchenko \\ Department of Ecology and \\ Environmental Management) \\ State Agrarian and Engineering \\ University in Podillia \\ Kamianets-Podilskyi, Ukraine \\ seludcenkolesa@gmail.com \\ Dmytro Skorobogatov \\ Department of Physics and Engineering \\ Discipline \\ State Agrarian and Engineering \\ University in Podillia \\ Kamianets-Podilskyi, Ukraine \\ dskorobogatov@i.ua
}

\author{
Taras Hutsol \\ Vice Rector for Educational, Scientific \\ and Pedagogical Affairs State Agrarian \\ and Engineering University in Podillia \\ Kamianets-Podilskyi, Ukraine \\ pro-gp@pdatu.edu.ua
}

\begin{abstract}
The present study determined that the essential factor of technogenic influence on the roadside landscapes is a motor complex that leads to the alienation of large territories, destabilizing of the natural ecosystems, the disarticulation of landscapes and an irreversible transformation of nature and territorial complexes in general. The significant influence of motor transport is the exhaust emissions with Carbon (II) oxide, Nitrogen oxides, hydrocarbons, aldehydes, soot (technical carbon), mineral dust, heavy metals, etc., that influence not only on the environment, but also on the health of the population. The migration and deposition of the pollutants that are produced by vehicle flows are caused by many factors of different genesis. In particular, this landscape topographic characteristics and the geochemical territory activity of natural and technogenic geo-ecosystems, structure of biocoenoses, presence of geochemical barriers (including artificially created), density, construction, transport, physical and geographical, social and economic features of transport network infrastructure, the intensity of transport flows, etc. Therefore, to ensure the environmentally safe operation of "car - road - environment" system should include a systematic approach to the development concept of the transport complex within the specific natural and man-made geo-ecosystems with developed automobile and communication networks that would provide not only its economic and transport feasibility, but also minimizing the anthropogenic transformation of natural and territorial complexes in general. To reduce eco-destructive impact we recommend to apply the developed design of forest of gas and dustproof lane road that substantially reduce the dangerous zone of influence.
\end{abstract}

Keywords-environmental security, model forest of gas and dustproof strips, road pollution.

\section{INTRODUCTION}

The establishment and operation of a national network of international transport corridors in Ukraine provide significant reduction of negative influence of transport complex on the roadside territories by creating environmental conditions on the highways, because the arterial and separate infrastructure roads refer to objects that make up an increased ecological danger [1,2].

In general, the density of roads in Ukraine is in 6.6 times lower than in France $(0.28$ and $1.84 \mathrm{~km}$ of highways per 1 square $\mathrm{km}$ of the country area). The length of expressway roads in Ukraine is $\sim 0.3$ thousand $\mathrm{km}$. By contrast, in Germany -12.5 thousand km, in France -7.1 thousand $\mathrm{km}$, but the level of funding per 1 kilometer of roads in Ukraine, respectively, in $5.5-6.0$ times smaller than in these countries [3]. The roads of the first category with high-speed multirow movement are absent on the territory of Ukraine. Most of them pass through the cities and don't meet the requirements of international transport corridors, and this fact leads to speed restriction and increase the danger level, including the environmental danger. The length of expressway roads in Ukraine of the European model is only $280 \mathrm{~km}$. It should be mentioned that the dynamic growth of the vehicle and the annual 5-percent growth of cars in Ukraine, leads to an increase in traffic intensity on the main roads up to $20 \%$. The transport and operational status of motorways is also unsatisfactory: $51.1 \%$ did not meet the equality requirements, and $39.2 \%$ - the durability requirements. Such low road transport and operational speed indicators of roads determine the low operational speed of vehicles that is in the 2-3 times lower on the roads of Ukraine than in Western European countries. In addition, these indicators lead to the rising of fuel and lubricant costs that are 30\% larger than the similar indicators in European countries [4].

Therefore, the increase in the motorization level and vehicle intensity on the highways leads to increasing their eco-destructive influence on a large scale. Therefore, to ensure the environment safe operation of transport complex a systematic approach to the state concept of

Print ISSN 1691-5402

Online ISSN 2256-070X

http://dx.doi.org/10.17770/etr2019vol1.4145

(C) 2019 Volodymyr Ivanyshyn, Lesia Sheludchenko, Taras Hutsol, Anatolii Rud, Dmytro Skorobogatov.

Published by Rezekne Academy of Technologies.

This is an open access article under the Creative Commons Attribution 4.0 International License. 
"car - road - environment" development that will provide a high transport performance, convenience and safety of vehicles, the preservation of the natural characteristics and properties of the roadside landscape should be applied.

The purpose of the research is to increase the level of environmental safety of natural and man-made geo eco-systems with high density of road network on the basis of artificially created geochemical barriers such as forest gas and dust-proofing zones that limit the migration and exhaust fumes emission caused by motor transport activity.

\section{MATERIALS AND METHODS}

The main results of the thesis were obtained on the basis of the system analysis and generalization of multivariate information about the dynamics of technological transformation of natural and man-made geo eco-system with developed vehicle networks (ecological optimization of the road network infrastructure, the development of scientific and methodological fundamentals of ecological safety of "car - road - environment"), the laws of thermodynamics, energy transfer and aerodynamics (the research on the processes of the vehicles gas and dust emission migration, landscape and spatial distribution of polluting ingredient deposition, the environmental effectiveness of protective road infrastructure) simulation modelling methods according to physical and dynamical analogy method (ecological and transport optimization of reference frame of transport network and the optimization of structural parameters of profile in cross-section reserve and technology automobile lanes). Analytical studies are performed on the basis of fractal geometry method (the study of the processes of dust aerosol adhesion on the landscape surfaces, compliance with environmental landscape safety that have been transformed road network).

\section{Results AND DISCUSSION}

The transformation of natural processes is identified, primarily, in terms of motorway influence through the roadside contamination by the following polluters: Carbon (II) oxide, Nitrogen oxides, hydrocarbons, aldehydes, soot (technical carbon), mineral dust, heavy metals, etc., that cause significant influence both on the environment and the health of the population.

The regression equation (often the third order) is widely used to calculate gas and fuel emissions, as well as the specific fuel costs of motor flow:

$$
\mathrm{Y}_{\mathrm{i}}=\mathrm{A}_{4} \cdot \mathrm{q}_{\text {an }}^{3}+\mathrm{A}_{3} \cdot \mathrm{q}_{\text {an }}^{2}+\mathrm{A}_{2} \cdot \mathrm{q}_{\mathrm{an}}+\mathrm{A}_{1}
$$

where $Y_{i}[\mathrm{~kg}]$ is the specific weight of a certain exhaust fumes ingredient, or specific fuel consumption by car flow;

$\mathrm{A}_{\mathrm{i}}$ - empirical coefficients

$q_{a n}[1 / \mathrm{s}]$ is the intensity of transport stream.

In this case:

$$
A_{i}=f\left(S_{i}, S_{j}\right)
$$

where $S_{i}, S_{j}$ is the share of motor vehicles equipped with diesel engines and the share of motor vehicles for passenger transportation in the total number of motor vehicles.
However, the current method for determining the balance of emissions that are produced by vehicle flow, in the full extent ignores such important transport operational signs of road network as geo-morphological nature of road, its technical condition, transport capacity and weather and climate conditions (road and climate zoning) natural and technogenic geo-ecosystems, the operational status of the vehicles in the motor transport flows and a number of other important indicators that significantly affect the level of technological transformation and environmental safety of natural territorial complex $[5,6]$.

That is why the generalized concept of maximum saturation of natural and technogenic geo-ecosystems by vehicle and road infrastructure is formed on the basis of the evaluation of the territory transport capacity i.e. the ability of the landscape of natural and territorial complex to ensure transport needs (in the areas for the location of stationary and moving objects in a motor complex, natural objects and recreational resources) without violation of the ecological balance. Transport capacity $D_{\max }$ is expressed in the form of maximum density of the road network and transport infrastructure within the natural territorial complex as $[1,6]$ :

$$
\begin{gathered}
D_{1}^{\mathrm{T}}=\frac{Y_{\mathrm{a}} \Pi_{\mathrm{H}} S_{\mathrm{a}}}{S_{\mathrm{T}}} \leq\left[D_{\text {max }}\right] \\
D_{\max }=\frac{Y_{\mathrm{a}}^{\max } \Pi_{\mathrm{H}}^{\max } S_{\mathrm{a}}}{S_{\mathrm{T}}}
\end{gathered}
$$

where $Y_{\mathrm{a}}$ is the level of motorization in the region, person/car;

$\Pi_{\mathrm{H}}$ is population density, person. $/ \mathrm{km}^{2}$;

$S_{\mathrm{a}}$ is given (taking into account the objects of the transport infrastructure) area for units of rolling stock vehicles, $\mathrm{m}^{2} / \mathrm{car}$; $\mathrm{km}^{2}$;

$S_{\mathrm{T}}$ is the total area of nature and territorial complex

$Y_{\mathrm{a}}^{\max }$ is maximum (on the basis of securing the transport needs of a region) level of motorization, person/ car (varies within the $0.45-0.5$ person/car

$\Pi_{\mathrm{H}} \max$ is population density, which provides favorable conditions, person $/ \mathrm{km}^{2}$, take $30-50$ person $/ \mathrm{km}^{2}$.

The ability of natural and technogenic geo-ecosystems to maintain the properties of the natural territorial complex within some environmentally safe amplitude is determined by the reproductive ability of the territory on the following basic indicators: atmospheric oxygen recovery, reproduction of surface water resources, soil and vegetative cover, restore tree and shrub plantings (, , , ) i.e. [6]. According to the values of the reproductive capacity of the area of the natural territorial complex through the generalized index of $\mathrm{I}_{\mathrm{p}}$ reproductions you can set the limit scope of the transport development of natural and technogenic geo eco-systems under each of the component and to determine the relevant indicators of the reproductive capacity of the area of the natural territorial complex to the indicators of the actual and future consumption of major biotic and abiotic components of the ecosphere in the result of trucking activity. 
Therefore, to implement the objectives of transport and environmental rationalization of transport network of natural and man-made geo ecosystems it is more advisable to use function that would be connected not only with the structure of the fleet of vehicles, and to a specific area of nature and territorial complex. Objective function in this case, will look like:

$$
f_{C \leq[\text { гдк }]}=\frac{S_{C \leq\left[г д К_{j}\right]}}{S} \rightarrow 100 \%
$$

Where is the total area of nature and territorial complex, $\mathrm{km}$;

is the area of nature and territorial complex, where the concentration $j$ of harmful substances that is produced by car flow in ground layers of atmospheric air does not exceed the value of the maximum allowable concentration.

In this case, the generalized evaluation of ecological safety in construction (reconstruction), repair and maintenance during the operation of the road can be used as a criterion for cumulative index (K), which is calculated for the "car - road - environment" giving the "weight" of the individual parameters of a state and territorial complex $[10,11]$ :

$$
K=\frac{S_{1} \alpha_{1}+S_{2} \alpha_{2}++S_{n} \alpha_{n}}{\alpha_{1}+\alpha_{2}++\alpha_{n}}
$$

where is the value of compliance degree of individual influence parameters on the objects of nature and territorial complex and regulatory requirements;

is the influence coefficient of "weight" and iparameter on the objects of nature and territorial complex at certain stages of its operation.

The integrated index (K) determines the level of ecological safety of "car - road - environment" system and is the basis for the development of strategies for ensuring the reduction of the anthropogenic influence of road network on the objects of nature and territorial complex [7]. Carrying out such a complex assessment of natural and technogenic geo eco-system with advanced motor transport network the risk factors should be taken into account and that arise in the operation of "car - road - environment" infrastructure systems. This level of operational security complex "car - road - environment" is defined by the formula:

$$
R=\sum_{i=1}^{m} P_{i} \lambda_{i} G_{i}
$$

Where is probability (frequency) of the development of i situation;

is probability (frequency) of development of i situation to some ultimate situation, which is characterized by the formation of the unacceptable situation for some negative impact; is the level of the effects caused by i situation to the infrastructure objects of man-made geo eco-system.

The results of the research. Therefore, the main task of the protection of the natural and man-made geoecosystem with developed vehicle networks from the influence of transport flow emissions is to develop such structures of transport infrastructure that would provide the intensification of exhaust fumes deposition at reserve and technology driving lanes (taking into account meteorological, weather and climatic conditions of nature and territorial complex) and would narrow the total width of the influence lanes of transport network.

In its turn, the lack of transport network protection leads to uncontrolled contamination of natural and technogenic geo ecosystem that depends on the contaminant migration, that produce the vehicle flows, the levels the chemical activity of these substances, weather, climate and meteorological conditions in the region, the characteristics of landscape and the underlaid surfaces of his objects, etc. [1,3].

In that context, on the basis of analysis the parameters were scientifically proved and the design constructions of the forest, gas and dustproof zones for their practical realization were developed. These constructions consider such factors as: road of category, intensity of transport flow, weather and climate, landscape characteristics of the territory and limit the impact of transport on the environment and provide sufficient level of ecological safety of the territory with developed road network. 1 [7].

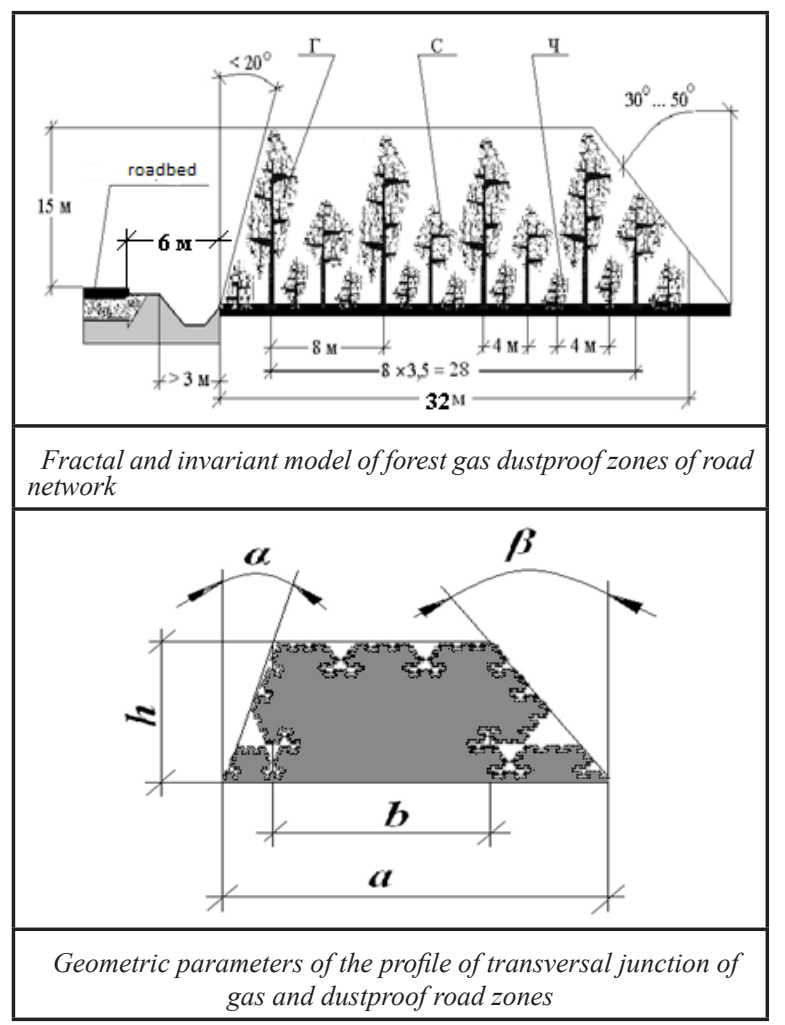

Fig.1. A model of forest, gas and dustproof road zones.

A characteristic feature of tree and bush type forest, gas and dustproof zone construction is trapezoid profile of its cross-section with different discharge angles of 
the avers (inverse to carriageway road) and reverse side surfaces. In this case, the angle of inclination $\alpha$ of avers forest belt surface is 1.5-2.5 times smaller than the $\beta$ angle of inclination of its reverse surface. Such geometry parameters of the cross-section of protective insulating type forest belt as a result of specific aerodynamic conditions of stripes wrap by air flows cause "the aerodynamic shadow" on its reverse side. The forest belt gas and dustproof zone construction is very effective in terms of protecting roadside areas with advanced road network from gaseous emissions that are produced by vehicle flow, and provide the decrease of pollution index of the atmosphere on the reverse side of the zone in comparison with its avers side for such ingredients as $\mathrm{CO}, \mathrm{N}_{x} \mathrm{O}_{y}, \mathrm{SO}_{2}$ is in $\sim 10.7$ times and the level of oxygen recovery of car flow is in $39-47 \%$.

To improve the dustproof properties of the gas and dustproof forest belt constructions the derivative constructions with thin planting of trees or with lacunar network in plant formation structure of forest belt can be applied (fig. 2) [8].

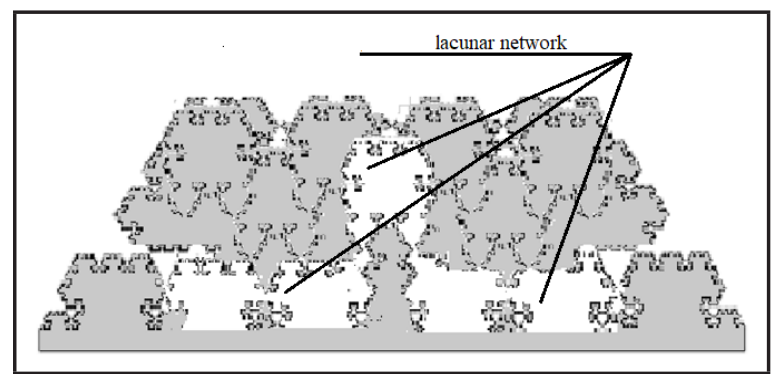

The model of forest gas and dustproof zones with lacunar net-

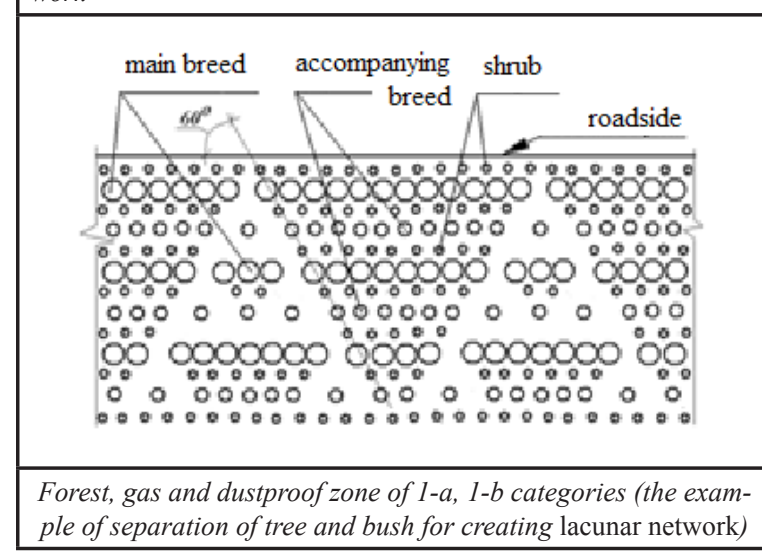

Fig. 2. The model of gas and dustproof road zones with lacunar network

Types and aerodynamic characteristics of fractal and lacunar model cross-section of gas and dustproof forest belt shown in Fig. 2 are defined, first of all, by its percolation (from the Latin percolare - "to flow") properties.

The intensity of the filtration properties of the forest belt will depend, in this case, on its percolation parameters and will be determined by some boundary value $L_{g r}$, that identifies the lack of percolation in fractal under the condition of $L<L_{g r}$. The following inequality describes the basic aerodynamic property of forest gas and filter type dustproof road stripe road that is defined as subpolar (from Latin "sub-colare" - almost "to leak") (fig. 3).

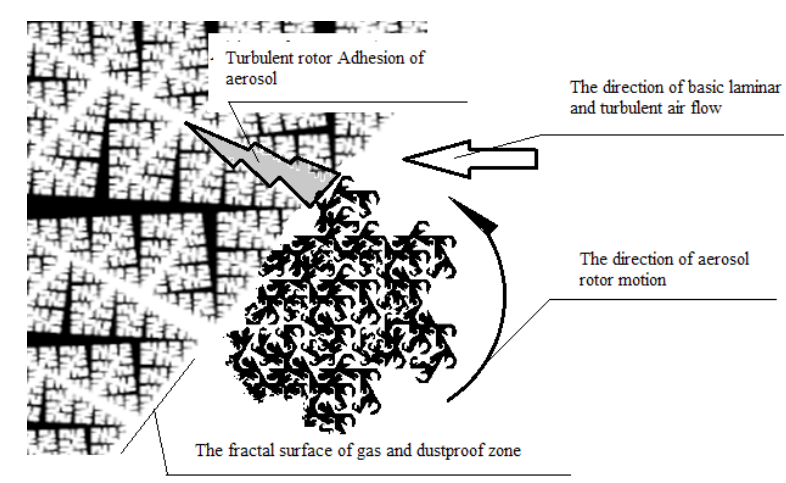

Fig. 3. Mineral dust adhesion of aerosol gas and dust clouds ejection with the surface of the obverse side of the gas and dustproof forest belt (adhesion process consists of a regular fractals)

The constructive integrity of a fractal invariance of artificially created lacunar cavities for such gas and dustproof forest belt to the original design ensures keeping its performance including indicators of gaseous pollutants $\left(\mathrm{CO}, \mathrm{CO}_{2}, \mathrm{SO}_{2}, \mathrm{~N}_{\mathrm{x}} \mathrm{O}_{\mathrm{y}}\right)$, that is produced by vehicle flows $[7,9]$.

It has been found that the design of gas and dustproof zones with a maze of lacunar cavities provides full deposition of mineral dust particles within the forest belt with factions $>150$ microns. Disperse particles of mineral dust from factions $<150$ microns only partly deposited within forest belt, and can remain disperse in the air aerosols. However, the mass fraction of not deposited dust pollutants does not exceed $0.04 \%$ in summer and $0.12 \%$ in winter from the general mass of mineral dust that is produced by car flow $[7,8]$.

The evaluation findings of developed constructions for each road category, performed according to lacunar degree as the expected value of the second-order ratio of "massive" area indicators of transverse section model of forest belt to the square of lacunar cavities are listed in Table 1 . by the formula:

$$
R=\frac{n}{\left(\frac{k}{\left(k_{\text {thinning }}\right)} 1\right)}
$$

Where $k$ is the total number of woody and shrubby plants on one step in all ranks of the forest belt;

$K_{\text {thinning }}$ is the total number of misses in planting of woody and shrubby plants in lacunar cavities on one step in all ranks of the forest belt landing;

TABLE I. FEASIBILITY STUDY OF USING $R$ - LACUNAR CONSTRUCTION FOREST AND DUSTPROOF LANE FOR AUTOMOBILE ROADS OF RELEVANT CATEGORIES

\begin{tabular}{|c|r|r|r|r|r|r|}
\hline $\begin{array}{c}\text { Category of } \\
\text { road }\end{array}$ & $\mathbf{1 a}$ & $\mathbf{1 0}$ & $\mathbf{2}$ & $\mathbf{3}$ & $\mathbf{4}$ & $\mathbf{5}$ \\
\hline $\begin{array}{c}\text { The intensity } \\
\text { of the motor } \\
\text { traffic flow, } \\
\text { car/hour }\end{array}$ & 15000 & 7000 & 2000 & 1000 & 500 & 200 \\
\hline $\begin{array}{c}\text { Planting lane } \\
\text { of forest belt }\end{array}$ & $\geq 17$ & 17 & 13 & 9 & 5 & 3 \\
\hline $\begin{array}{c}\text { Calculation } \\
\text { of } R\end{array}$ & $7,08>>1$ & $7,08>>1$ & $4,19>1$ & $2,19>1$ & $0,81<1$ & $0,25<1$ \\
\hline
\end{tabular}




\section{Conclusions}

The results of the research make it possible to conclude that exhaust fumes transfer is determined by the design characteristics of the protective road zones. The analysis of feasibility study on using forest gas and dustproof car zones of lacunar construction demonstrates their feasibility for roads of 1a, 1b, 2 and 3 categories. At the same time for roads of categories 4 and 5 forest gas and dustproof zones of general construction with planting lane of trees and bushes.

\section{REFERENCES}

[1] V.F. Babkov, Landscape design of automobile roads. Moscow: Transport. Moskow: Transport, 1980, pp.189.

[2] Engineering ecology Инженерная экология /Edited by V.T. Medvedyev. Moskow: Gaydariki, 2002. Pp. 687

[3] Ye. Alekseyeva. The impact on the environment: opportunities for public. [Edited by O.Kravchenko] - Publishing company «Manuskript»- Lviv, 2017. Pp. 36.

[4] B.A.Sheludchenko. Introduction to the design of natural and technogenic geo eco-systems . Kamyanets-Podilskyi: PDATU, 2014. Pp. 170

[5] B.B. Mandelbrot, The Fractal Geometry of Nature. W.H. Freeman and Company, 1983. 468 p.
[6] G.I. Rudko, O.M. Adamenko, Constructive geoecology: scientific basics and practical implementation. Edited by G.I. Rudko. Ch.: «Maklaut», 2008. 320 p.

[7] L.S. Sheludchenko, The design development of gas and dustproof road zones. Kamyanets-Podilskyi: PDATU, 2015. Pp. 134

[8] L.S. Sheludchenko, B.A. Sheludchenko, S.V. Voznyuk, The analytical study of lacunar parameters of forest gas and dustproof road zones. Scientific and technical Journal "Environmental safety and balanced resource usage" Special edition. IvanoFrankivsk: IFNTUNG, 2014. pp.56-60.

[9] L.S. Sheludchenko, Environmental safety of landscapes of natural territorial complexes transformed by the vehicle networks Scientific and technical. Journal "Environmental safety and balanced resource usage” № 2/2017 (24). Kremenchuk: KrNU, 2017. pp. 9-13.

[10] T.D. Hutsol, O.V. Shelega, O.V. Zelenskyi, Features of planning road repair projects. East European Magazine of Advanced Technology. Kharkiv, 2012. Pp. 38-41.

[11] O.V.Sydorchuk, P.M.Lub, V.S.Spichak, Methodology of production and technological risk management based on statistical simulation of project work. East European Magazine of Advanced Technology. Vol.1. Kharkiv: Tekhnologichnyi centr, 2010. Pp. 8992.

[12] A.V. Pechenyuk, T.D. Hutsol, Modern information technologies in transport logistics. Bulletin SNU im. V.Dalya, №6. 2010. pp. $1-4$. 